\title{
Movilidad educativa intergeneracional absoluta y relativa en México. Diferencias por sexo y cohortes de nacimiento de 1952 a 1991
}

\author{
Santiago Andrés Rodríguez \\ Universidad Nacional Autónoma de México. \\ Instituto de Investigaciones sobre la Universidad y la Educación \\ sarodriguez513@gmail.com
}

Recepción: 30-03-2019

Aceptación: 24-11-2019

Publicación: 01-07-2020

\section{Resumen}

El objetivo del artículo es analizar las oportunidades absolutas y relativas de movilidad educativa intergeneracional por sexo y cohortes de nacimiento en México. Para ello se utilizan datos actuales que provienen del Módulo de Movilidad Social Intergeneracional (MMSI) de 2016 del INEGI. El enfoque metodológico se apoya en el cálculo de medidas absolutas de movilidad y en la estimación de modelos log lineales mediante los cuales se obtienen medidas relativas de movilidad. Por un lado, las medidas absolutas muestran un predominio de la movilidad ascendente frente a la inmovilidad y a la movilidad descendente tanto para los hombres como para las mujeres a lo largo del tiempo. No obstante, la magnitud de la movilidad educativa ascendente presenta algunas diferencias por sexo a través de las cohortes de nacimiento bajo estudio. Por otro lado, las medidas relativas indican que las barreras a la movilidad cambian significativamente para los hombres y las mujeres a lo largo del tiempo. Para las mujeres se destaca un incremento de las barreras en los extremos de la distribución educativa. En cambio, para los hombres las barreras a la movilidad disminuyen en la parte baja de la distribución educativa y se incrementan en el acceso a la Educación Media Superior y Superior. El artículo finaliza con una breve discusión sobre líneas futuras de investigación sobre movilidad educativa intergeneracional en México.

Palabras clave: estratificación social; oportunidades estructurales; desigualdad de oportunidades educativas; medidas absolutas; modelos log lineales; barreras a la movilidad 
Abstract. Absolute and relative intergenerational educational mobility in Mexico: Differences by sex and birth cohorts from 1952 to 1991

The purpose of this article is to analyze the absolute and relative opportunities of intergenerational educational mobility by sex and birth cohorts in Mexico. The study uses current data from the intergenerational social mobility module of the National Statistics Institute (INEGI) of Mexico for 2016. The methodological approach was based on social mobility rates and three-way loglinear models to explore changes in barriers to educational mobility. The picture emerging from these findings depicts a society that maintained high rates of structural educational mobility, with a prevalence of upward mobility for both men and women over time. Nevertheless, when controlling for structural mobility, it is observed that barriers to mobility change significantly for men and women over time. For women, the barriers increase at the extremes of the educational distribution. For men, barriers decrease in the lower part of the educational distribution and increase in access to upper secondary and higher education. The article concludes with a discussion of future avenues of research for educational mobility studies in Mexico.

Keywords: Social stratification; structural opportunities; inequality of educational opportunity; absolute mobility rates; loglinear model; barriers to mobility

\section{Sumario}

\section{Introducción}

2. Andamiaje conceptual y estudios antecedentes sobre movilidad educativa intergeneracional en México

3. Metodología: datos, variables y estrategia de análisis

4. Estructura del sistema educativo, incremento en la escolaridad y movilidad educativa intergeneracional absoluta
5. Barreras a la movilidad educativa intergeneracional

6. Repaso de resultados y discusión

Referencias bibliográficas

Anexo

\section{Introducción}

El informe de investigación «Desigualdades en México 2018» ofrece un diagnóstico de las desigualdades que prevalecen en el país en tres áreas clave: educación, ingreso y movilidad social, y trabajo. El resumen ejecutivo del informe destaca: 1) las desigualdades educativas siguen siendo severas en la calidad de los aprendizajes y la finalización del nivel medio superior, con acentuadas diferencias entre población indígena y no indígena; 2) las personas nacidas en condiciones de pobreza tienen mínimas posibilidades de ascenso social. Al desagregar el análisis por sexo, las mujeres que nacen en hogares pobres tienen mayor probabilidad de mantenerse en condiciones de marginación en la transición a la vida adulta. Además, las mujeres que trabajan reciben en promedio menores ingresos que los hombres. Y por último, 3) disminuyeron las oportunidades para acceder a empleos de calidad. A partir de la recesión 
económica del 2008, se observa una continua convergencia salarial a la baja con un marcado deterioro en las remuneraciones de los trabajadores formales (COLMEX, 2018).

La persistencia de la desigualdad sugiere que la sociedad mexicana se caracteriza por un entramado de relaciones sociales cerradas donde los límites de clase son rígidos y la movilidad social intergeneracional es baja. Es decir, el destino educativo y ocupacional (de clase) de las personas se encontraría fuertemente determinado por el origen social familiar. Esta afirmación constituye una hipótesis que requiere de estudios basados en evidencia empírica. Los resultados de investigaciones recientes sobre estratificación social y movilidad de clase intergeneracional indican que, en términos absolutos, predomina una movilidad de clase de "corto alcance» con acceso a oportunidades de vida similares y, en términos relativos, el patrón movilidad se encuentra dominado por efectos jerárquicos, evidenciado una rigidez en la base y en la cima de la estructura social. Además, reportan un incremento de la asociación entre orígenes y destinos de clase en las cohortes más jóvenes (Solís, 2016b).

Este artículo se concentra en el análisis de la movilidad educativa intergeneracional, es decir, la medición de la relación que existe entre el nivel de escolaridad de los padres y el nivel de escolaridad de los hijos. El interés principal desde esta perspectiva analítica radica en «re-conceptualizar la desigualdad social en educación como procesos de movilidad intergeneracional en logros educativos» (Pfeffer, 2008: 547). Además, cabe destacar que la educación cumple un doble papel en el proceso de estratificación y movilidad social. Por un lado, puede constituir un canal de movilidad social ascendente. Por otro lado, puede reproducir la desigualdad entre generaciones. Así, por ejemplo, para las personas de orígenes sociales bajos el acceso a la Educación Superior podría aumentar sus probabilidades de experimentar movilidad social ascendente.

El objetivo del artículo es analizar las oportunidades absolutas y relativas de movilidad educativa intergeneracional por sexo y cohortes de nacimiento en México. El artículo se organiza en cuatro grandes secciones. En la primera sección se plantean los conceptos teóricos que guían el estudio y se reconstruye brevemente el debate sobre estratificación y movilidad social en México con énfasis en resultados de investigaciones sobre movilidad educativa intergeneracional. La segunda sección refiere al diseño metodológico y se describe la fuente de datos, las variables y la estrategia de análisis. En la tercera sección se analizan las pautas absolutas y relativas de movilidad educativa intergeneracional por sexo y cohortes de nacimiento, y para finalizar, en la cuarta sección, se repasan los resultados principales y se plantean las consideraciones finales.

El artículo apunta a continuar y extender una tradición en investigación en el campo de los estudios sobre estratificación social y desigualdad de oportunidades educativas en México incorporando datos actuales que provienen de una encuesta oficial aplicada a nivel nacional. Los resultados buscan contribuir a la discusión teórica y empírica sobre los patrones de movilidad educativa intergeneracional distinguiendo similitudes y diferencias entre hombres y mujeres a lo largo del tiempo. 


\section{Andamiaje conceptual y estudios antecedentes sobre movilidad educativa intergeneracional en México}

Los estudios sociológicos que analizan la reproducción de la desigualdad social distinguen entre la desigualdad de condiciones y la desigualdad de oportunidades. La desigualdad de condiciones refiere a las diferencias en la distribución de bienes valiosos como educación, ingreso o riqueza en un momento determinado en el tiempo. En cambio, la desigualdad de oportunidades alude a la influencia de las características socioeconómicas de origen sobre el logro educativo y ocupacional de las personas (Breen y Jonsson, 2005; Torche, 2010). La movilidad intergeneracional es un importante indicador de la desigualdad de oportunidades en la sociedad porque

...al contrastar los cambios entre padres e hijos es posible cuantificar el grado de transmisión intergeneracional de posiciones sociales, y por tanto incorporar un tema central de los estudios de estratificación social, que es el análisis de la desigualdad de oportunidades (Solís, 2007: 27).

La movilidad educativa intergeneracional se observa entre la posición del padre —origen educativo - y la posición del hijo/a — destino educativo. Las investigaciones sobre movilidad educativa intergeneracional diferencian entre la movilidad absoluta y la movilidad relativa. La movilidad absoluta representa el patrón de flujos de orígenes a destinos que puede observarse en la tabla de movilidad intergeneracional (Breen et al., 2016). Las medidas clásicas de movilidad absoluta son las tasas totales, las tasas de entrada «inflows» y de salida "outflows» que derivan de las tablas de movilidad intergeneracional (Hout, 1983).

La movilidad relativa implica contrastar las oportunidades relativas que tienen las personas de diferentes orígenes sociales de alcanzar destinos determinados, una vez controlada la movilidad absoluta (en este caso, controlando el cambio en las distribuciones educativas de orígenes y destinos). En este sentido, permite una aproximación a la medición de la desigualdad de oportunidades de movilidad entre personas con distintos orígenes sociales, reflejando el patrón de «fluidez social» de una sociedad. El análisis de la movilidad relativa o fluidez social se basa en el cálculo de razones de momios (odds ratios) que expresan la asociación entre orígenes y destinos «neta» de los efectos del cambio estructural. Asimismo, las razones de momios son los elementos básicos de los modelos log lineales que se utilizan frecuentemente en el análisis de la movilidad intergeneracional relativa (Erikson y Goldthorpe, 1992; Breen, 2004; Goldthorpe, 2010).

Desde la perspectiva sociológica de la estratificación y desigualdad social, Solís (2016b) identifica dos grandes etapas en los estudios sobre movilidad social intergeneracional en México. Durante la primera etapa, que transcurre entre mediados de los años sesenta y los setenta, se realizaron investigaciones empíricas sobre la movilidad social intergeneracional en Monterrey (Balán et al., 1977) y en la Ciudad de México (Muñoz et al., 1977; Contreras, 1978). El objetivo general de estas investigaciones consistió en analizar los efectos de los 
cambios sociales que experimentaron las sociedades (p. ej. industrialización por sustitución de importaciones, migración rural-urbana, urbanización, etcétera) sobre los patrones de estratificación y movilidad social. La segunda etapa inicia a finales de los años noventa en el marco de la discusión sobre

...si el llamado «cambio estructural» alteró significativamente la estratificación social y, si tal era el caso, cuáles serían las características del nuevo régimen de movilidad social, tanto en términos de los patrones de movilidad social como de la fluidez general de la estructura social (Solís, 2011: 285).

Las investigaciones sobre estratificación y movilidad social de la segunda etapa comienzan a utilizar datos que provienen de encuestas aplicadas a nivel nacional — se expande la cobertura geográfica antes restringida a algunas ciudades del país-, tienden a incorporar a las mujeres en los análisis empíricos sobre la movilidad social intergeneracional — tradicionalmente excluidas de los estudios sobre estratificación social- $y$, por último, se esfuerzan por aplicar técnicas estadísticas - p. ej. modelos log lineales y log multiplicativosque permiten avanzar no solo en términos metodológicos, sino también en la medición de la fluidez de los regímenes de estratificación social. Específicamente, las investigaciones de la segunda etapa se concentraron en el análisis de la movilidad intergeneracional ocupacional (de clase social) y educativa, en la medición de la movilidad social subjetiva y, desde la economía, en la movilidad intergeneracional en los ingresos o la riqueza.

Tomados en conjunto, los resultados de las investigaciones sobre movilidad educativa intergeneracional absoluta y relativa de la segunda etapa indican que: 1) los hijos/as tienen en su mayoría mejores niveles de escolaridad que sus padres; 2) las tasas absolutas de movilidad educativa intergeneracional son altas; 3 ) además, las tasas absolutas muestran un predominio de la movilidad educativa ascendente frente a la descendente y la inmovilidad (Solís, 2007; Hoyos et al., 2010; CEEY, 2012; Yaschine Arroyo, 2015); 4) sin embargo, las tasas relativas de movilidad muestran un incremento de la asociación entre orígenes y destinos educativo a lo largo del tiempo. En otras palabras, independientemente de la incidencia de la movilidad estructural se observa una mayor rigidez en el régimen de movilidad educativa intergeneracional (menor nivel de igualdad de oportunidades). Y por último, 5) se restringen las oportunidades de acceder al nivel medio superior y superior para los hijos/ as de padres con niveles educativos bajos, sobre todo en las cohortes más jóvenes (Solís, 2007; Torche, 2010; Campos Vázquez, 2016; CEEY, 2018; Solís, 2018).

\section{Metodología: datos, variables y estrategia de análisis}

Los datos surgen del Módulo de Movilidad Social Intergeneracional (MMSI) de 2016 levantado por el Instituto Nacional de Estadística y Geografía (INEGI). El diseño de la muestra del MMSI es el empleado en la Encuesta 
Nacional de Hogares y se caracteriza por ser probabilístico, por tanto, los resultados pueden generalizarse a toda la población; a su vez es bietápico, estratificado y por conglomerados, donde la unidad última de selección es la persona. La información es representativa de la población entre 25 a 64 años residentes en viviendas particulares a nivel nacional. El tamaño de la muestra es de 25.634 casos (INEGI, 2016). ${ }^{1}$ El MMSI comprende datos actuales y retrospectivos (14 años del encuestado/a) que permiten contrastar el origen y el destino de las personas en tres dimensiones: educativa, ocupacional y económica.

El análisis de la movilidad educativa intergeneracional se apoya en tablas de doble entrada que contratan los orígenes y los destinos educativos. La muestra final sobre la cual se avanza en términos analíticos es de 24.382 casos (10.326 son hombres —el 42,4\%-y 14.056 son mujeres —el 57,6 \%-). Cuando los encuestados/as indicaron no recordar o no conocer el nivel de escolaridad del padre se asignó la información proveniente de la madre - y viceversa(Jorrat, 2010; Solís, 2013; Leone, 2017). ${ }^{2}$

A continuación, se definen las variables principales y sus sistemas de categorías. La clasificación para medir los orígenes y los destinos educativos retoma los grandes niveles del Sistema Educativo Nacional: Primaria, Secundaria, Educación Media Superior y Superior (SEP, 2000). Orígenes educativos: refiere al máximo nivel de escolaridad alcanzado ya sea por el padre o por la madre del encuestado/a. Destinos educativos: refiere al máximo nivel de escolaridad alcanzado por el encuestado/a. Las variables orígenes y destinos educativos tienen 6 categorías:

(1) Sin escolaridad: personas que no asistieron a la escuela o que no aprobaron ningún grado.

(2) Primaria incompleta: personas con uno a cinco grados aprobados de Primaria.

(3) Primaria completa: personas con seis grados aprobados de Primaria —incluye estudios técnicos o comerciales con Primaria terminada.

(4) Secundaria: personas con al menos un grado aprobado de Secundaria —incluye estudios técnicos o comerciales con Secundaria terminada.

(5) Educación Media Superior (EMS): personas con al menos un grado aprobado de Preparatoria o Bachillerato —incluye Normal básica.

(6) Superior: personas con uno a cuatro años aprobados de Educación Superior (estudios técnicos o comerciales con Preparatoria terminada, Normal de Licenciatura, Licenciatura o Profesional) —incluye Maestría y Doctorado. ${ }^{3}$ Las investigaciones recientes sobre patrones de movilidad educativa intergeneracional en México utilizan un sistema de categorías semejante al propuesto (Solís, 2007; 1918; Torche, 2010; Hoyos et al., 2010; CEEY, 2012).

1. Para mayor información sobre las muestra, véase <https://www.inegi.org.mx/programas/ $\mathrm{mmsi} / 2016 />$.

2. Aproximadamente, $5 \%$ de los encuestados/as no proporcionaron información sobre el nivel de escolaridad del padre y de la madre - 1.252 valores perdidos.

3. Las categorías Secundaria, EMS y Superior no distinguen entre ciclo incompleto y completo. 
El análisis de la movilidad educativa intergeneracional se desagrega por las variables sexo - (1) hombres y (2) mujeres- ${ }^{4}$ y cohorte de nacimiento. En términos sociológicos, los miembros de una cohorte de nacimiento comparten la exposición a las mismas condiciones sociohistóricas que les tocó vivir en un momento en el tiempo (Ryder, 1965). La crítica metodológica al análisis de cohortes con encuestas transversales es que no permite distinguir entre efectos de edad, cohorte y período en la interpretación del cambio (Glenn, 2005). El efecto edad es controlado al seleccionar a personas de 25 años y más. $\mathrm{Al}$ no poder distinguir entre los efectos cohorte y período se tratará de brindar ambas interpretaciones en el cambio observado (Torche, 2010). La variable cohorte de nacimiento comprende a los nacidos entre 1952 y 1991 y tiene 4 categorías: (1) $1952-1961,(2) 1962-1971$, (3) $1972-1981$ y (4) 1982-1991.5

A partir de las tablas de movilidad educativa intergeneracional por sexo y cohortes de nacimiento se calculan las siguientes medidas absolutas:

- Porcentajes de la distribución marginal de orígenes y destinos educativos.

— Índice de disimilitud (ID). Se obtiene a partir de la fórmula:

$$
\mathrm{ID}=\sum_{i=1}^{n}\left|\frac{O_{i+}-D_{i+}}{2}\right|
$$

Donde $\mathrm{O}_{i+}$ refiere a la frecuencia relativa marginal de los casos en la categoría $i$ en los orígenes y $\mathrm{D}_{i+}$ como la misma frecuencia relativa en los destinos

4. Los tabulados para el total de la población — personas de 25 a 64 años— pueden solicitarse por mail al autor.

5. Si se selecciona la edad de 18 años como crucial en la trayectoria educativa, los miembros de las cuatro cohortes debieron experimentar la transición a la Educación Superior en diferentes contextos socio-históricos. Un repaso breve «a mano alzada» indicaría que la cohorte 1952-1961 transita en el período posterior a la represión al movimiento estudiantil de 1968 y bajo la presidencia de Luis Echeverría Álvarez (1970-1976). La cohorte, 19621971, durante la última etapa de la presidencia de José López Portillo (1976-1982) y en el transcurso de la presidencia de Miguel de la Madrid (1982-1988), cuya política económica se caracterizó por la liberalización del comercio, el pacto de solidaridad económica y la disminución de la participación del Estado en la economía. La cohorte 1972-1981, durante una etapa de la presidencia de Carlos Salinas de Gortari (1988-1994) y transcurso de la presidencia de Ernesto Zedillo Ponce de León (1994-2000). Durante el sexenio de Salinas se reduce al mínimo la intervención del Estado en la economía, se firma el Tratado de Libre Comercio de América del Norte, se aplican programas de privatización y de estabilización económica. Para el año 1994 la pobreza de patrimonio representa el 55,6 \% y el índice de Gini alcanza el 0,477 (Székely, 2005). El primero de enero tiene lugar el levantamiento del EZLN en Chiapas y el 23 de marzo asesinan al candidato a la presidencia Luis Donaldo Colosio. Cuando inicia el sexenio de Zedillo se establece la libre flotación cambiaria y el precio del dólar se incrementa cerca del 114 \% entre 1994 y 1995, impactando en el nivel de bienestar de la población. Este período estuvo marcado por la "crisis del tequila». En abril de 1999 se desata una huelga en la UNAM contra la modificación del Reglamento General de Pagos. Por último, la cohorte 1982-1991 transita en el transcurso del gobierno de Vicente Fox Quesada (2000-2006), caracterizado por el inicio de la alternancia política en la presidencia de la república. 
educativos. El valor del índice de disimilitud comprende entre 0 y 1 o entre 0 y 100 si se expresa en porcentaje, índica el porcentaje mínimo de casos que deberían cambiar de categoría para que las distribuciones marginales de orígenes y destinos educativos sean idénticas (Solís, 2016a). Es importante señalar que el índice de disimilitud frecuentemente se interpreta como una medida de movilidad estructural: movimientos intergeneracionales que responden a transformaciones de tipo estructural (p. ej. cambios sociales, económicos y demográficos).

- Medidas absolutas de movilidad. Son los porcentajes de casos que, respecto del total, experimentaron distintos tipos de movilidad (ascendente y descendente) o inmovilidad (herencia educativa).

Con el propósito de evaluar la movilidad educativa intergeneracional relativa, se aplican modelos log lineales de tres vías que incorporan simultáneamente los orígenes educativos, los destinos educativos y las cohortes de nacimiento. Es decir, se trata de tablas de triple entrada de 6 orígenes educativos $\mathrm{x} 6$ destinos educativos $\mathrm{x} 4$ cohortes de nacimiento $=144$ celdas para hombres y mujeres. Específicamente, se utilizan tres modelos log lineales de uso frecuente en la investigación sobre movilidad intergeneracional relativa: independencia condicional, asociación homogénea y asociación condicional (Agresti, 2007).

El interés principal al ajustar modelos log lineales se encuentra en los parámetros de interacción entre orígenes y destinos que definen el patrón de asociación. La bibliografía especializada sobre estratificación y movilidad social describe diversos patrones de asociación: cuasi independencia, esquinas cruzadas, simetría, topológicos (o de nivel), entre otros (Hout, 1983; Powers y Xie, 2000; Agresti, 2007; Treiman, 2009). Específicamente, en los modelos de asociación homogénea y asociación condicional aplicados, el patrón de asociación entre orígenes y destinos se modela mediante parámetros de cruces (crossing parameters). El supuesto general indica que «las diferentes categorías de una variable nominal presentan un grado de dificultad para ser cruzadas» (Powers y Xie, 2000: 117). En otras palabras, los parámetros de cruce miden el grado de dificultad que experimentan las personas para cruzar barreras entre niveles educativos adyacentes. Teniendo en cuenta que la tabla de movilidad intergeneracional incluye 6 categorías educativas para orígenes y destinos, se estiman 5 parámetros de cruce entre: sin escolaridad y Primaria incompleta (Cr1), Primaria incompleta y Primaria completa $(\mathrm{Cr} 2)$, Primaria completa y Secundaria (Cr3), Secundaria y EMS (Cr4) y EMS y Superior (Cr5) (véase la matriz de diseño de los parámetros de cruces en el anexo). ${ }^{6}$ Estos modelos permiten estudiar «el grado de movilidad experimentado, las principales barreras que dificultan la movilidad

6. Los parámetros de cruces son simétricos. Para un mayor detalle técnico sobre la especificación de los parámetros de cruce, véase Powers y Xie (2000) y Treiman (2009). 
educacional, así como el cambio de dichas barreras a lo largo del tiempo» (Torche, 2010: 74). ${ }^{7}$

\section{Estructura del sistema educativo, incremento en la escolaridad $\mathrm{y}$ movilidad educativa intergeneracional absoluta $^{8}$}

En México, la Secretaria de Educación Pública (SEP) se encarga de diseñar, ejecutar y coordinar las políticas en materia de educación. El Sistema Educativo Nacional (SEN) proporciona tres tipos educativos: básico, medio superior y superior. El tipo básico comprende el Preescolar, que se cursa entre los 3 y 5 años y tiene una duración de 3 años; la Primaria se compone de seis grados y se debe cursar en un rango de edad de los 6 a los 11 años; y la Secundaria —obligatoria desde 1993tiene tres grados que se cursan entre los 12 a 14 años. La Secundaria se acredita mediante un certificado oficial que es un requisito para ingresar a la Educación Media Superior. El tipo educativo de Media Superior, que comprende el Bachillerato o equivalente y la Educación Profesional sin antecedentes de Bachillerato o equivalente, es obligatorio desde 2012 tras la reforma a los artículos $3^{\circ}$ y $31^{\circ}$ de la Constitución Política (DOF, 2012, 9 de febrero), y se planteó alcanzar su universalización en el ciclo escolar 2021-2022. La Educación Media Superior se cursa, por lo general, en tres años en un rango de edad de los 15 a los 17 años. Por último, la Educación Superior comprende el nivel técnico superior universitario, licenciatura y posgrado, y para el ingreso se requiere el certificado oficial que acredite el Bachillerato. Cabe señalar que la reforma de 2019 a los artículos $3^{\circ}, 31^{\circ}$ y $73^{\circ}$ de la Constitución Política estableció que la obligatoriedad de la Educación Superior corresponde al Estado (DOF, 2019, 15 de mayo).

La Primaria, obligatorita desde 1934, alcanza una cobertura casi universal en el ciclo escolar 2016-2017 (tasa de cobertura neta = 98,4\%). En las últimas décadas también se ha incrementado la cobertura en los niveles Medio Superior y Superior: pasó de 34,3 \% en el ciclo escolar 2000-2001 al 62 \% en el 20162017 en el nivel Medio Superior, y de 19,2 \% en el ciclo escolar 2000-2001 al 38,4\% en el ciclo 2016-2017 para el nivel Superior (SNIEG, 2018). Pese a este incremento es difícil alcanzar la meta de la cobertura universal en el nivel Medio Superior para el ciclo 2021-2022 y, además, un bajo porcentaje de estudiantes ingresa al nivel Superior de educación.

El Sistema Educativo Nacional (SEN) se caracteriza por la heterogeneidad de la oferta educativa. Así, por ejemplo, el nivel Medio Superior se ofrece en

7. Otra opción sería aplicar un modelo log-multiplicativo - p. ej. UNIDIFF- para analizar la fuerza de la asociación entre orígenes y destinos educativos a lo largo de las cohortes de nacimiento. Ahora bien, este modelo «es muy poderoso para detectar una tendencia dominante en los datos, pero también puede resultar relativamente crudo para describir con exactitud los cambios que han ocurrido" (Vallet, 2016: 269).

8. Un análisis antecedente sobre movilidad educativa absoluta por sexo y cohortes de nacimiento que emplea 5 categorías educativas para orígenes y destinos y aplica otras estrategias metodológicas (p. ej. razones de cambio intergeneracional, medidas de movilidad de "corta y larga distancia», porcentajes de salida outflows, entre otras) puede verse en Rodríguez (2019). 
Cuadro 1. Estructura y dimensión del sistema educativo.

\begin{tabular}{|c|c|c|c|c|c|c|}
\hline $\begin{array}{l}\text { Tipo } \\
\text { educativo }\end{array}$ & Nivel educativo & $\begin{array}{l}\text { Tipo de servicio o } \\
\text { modelo educativo }\end{array}$ & $\begin{array}{l}\text { Edad ideal } \\
\text { o típica }\end{array}$ & $\begin{array}{l}\text { Duración } \\
\text { en años }\end{array}$ & Carácter & $\begin{array}{c}\text { Cobertura } \\
\text { ciclo* }^{*} \\
2016-2017\end{array}$ \\
\hline \multirow[t]{3}{*}{$\begin{array}{l}\text { Educación } \\
\text { Básica }\end{array}$} & Preescolar & $\begin{array}{l}\text { Cendi } \\
\text { General } \\
\text { Indígena } \\
\text { Comunitario }\end{array}$ & 3 a 5 & 3 & $\begin{array}{l}\text { Obligatoria a par- } \\
\text { tir de } 2002\end{array}$ & $73 \%$ \\
\hline & Primaria & $\begin{array}{l}\text { General } \\
\text { Indígena } \\
\text { Comunitario }\end{array}$ & 6 a 11 & 6 & $\begin{array}{l}\text { Obligatoria a par- } \\
\text { tir de } 1934\end{array}$ & $98,4 \%$ \\
\hline & Secundaria & $\begin{array}{l}\text { General } \\
\text { Técnica } \\
\text { Telesecundaria } \\
\text { Comunitaria } \\
\text { Para trabajadores }\end{array}$ & 12 a 14 & 3 & $\begin{array}{l}\text { Obligatoria a par- } \\
\text { tir de } 1993\end{array}$ & $86,2 \%$ \\
\hline $\begin{array}{l}\text { Educación } \\
\text { Media } \\
\text { Superior }\end{array}$ & $\begin{array}{l}\text { Bachillerato o equi- } \\
\text { valente y Educación } \\
\text { Profesional sin ante- } \\
\text { cedente de Bachille- } \\
\text { rato o equivalente }\end{array}$ & $\begin{array}{l}\text { Bachillerato general } \\
\text { Bachillerato } \\
\text { tecnológico } \\
\text { Profesional } \\
\text { tecnológico }\end{array}$ & 15 a 17 & $2-5$ & $\begin{array}{l}\text { Obligatoria a par- } \\
\text { tir de } 2012\end{array}$ & $62 \%$ \\
\hline \multirow[t]{2}{*}{ Superior } & Licenciatura & $\begin{array}{l}\text { Educación normal } \\
\text { Universitaria y } \\
\text { tecnológica }\end{array}$ & - & - & $\begin{array}{l}\text { Aprobación de } \\
\text { la obligatoriedad } \\
\text { mayo } 2019\end{array}$ & $38,4 \%$ \\
\hline & Posgrado & $\begin{array}{l}\text { Especialidad } \\
\text { Maestría } \\
\text { octorado }\end{array}$ & - & - & & \\
\hline
\end{tabular}

* Nota: tasa neta en Primaria, Secundaria y Educación Media Superior y tasa bruta en el nivel Superior.

Fuente: López y Rodríguez (2019).

las modalidades de Bachillerato general, Bachillerato tecnológico y Bachillerato profesional técnico (INEE, 2018). Con respecto al tipo de sostenimiento, predomina el sector público por sobre el privado (81,2\% público y $18,8 \%$ privado según la matrícula para el ciclo 2016-2017) (SEP, 2017). Además, en el sector público la oferta distingue entre bachilleratos de universidades (UNAM, IPN, UAEM) y planteles incorporados a Instituciones de Educación Superior (IES) que permiten el acceso al nivel superior. En el sector privado la oferta institucional también es heterogénea, dado que existen escuelas de élite y otras de bajo prestigio con menores costos de colegiatura. Finalmente, para ingresar a la Educación Media Superior la mayoría de las escuelas — privadas y públicas - exige la presentación del Examen Nacional de Ingreso a la Educación Media Superior (EXANI I) a cargo del Centro Nacional de Evaluación (CENEVAL). En la Zona Metropolitana de la Ciudad de México, el acceso a instituciones públicas se regula por el Concurso de Ingreso a la Educación Media Superior (COMIPEMS) (SEP, 2000). 
Cuadro 2. Trayectoria educativa de las cohortes de nacimiento. Grado promedio de escolaridad de los hombres y las mujeres por cohorte de nacimiento.

\begin{tabular}{lccccccc}
\hline Cohortes & $\begin{array}{c}\text { Edad al momento } \\
\text { de la encuesta }\end{array}$ & $\begin{array}{c}\text { Año entrada } \\
\text { Primaria }\end{array}$ & $\begin{array}{c}\text { Año entrada } \\
\text { Secundaria }\end{array}$ & $\begin{array}{c}\text { Año entrada } \\
\text { Educación Media } \\
\text { Superior }\end{array}$ & $\begin{array}{c}\text { Año entrada } \\
\text { Educación } \\
\text { Superior }\end{array}$ & Hombres & Mujeres \\
\cline { 8 - 9 } $\begin{array}{l}\text { Cohorte } \\
1952-1961\end{array}$ & $55-64$ & $1958-1967$ & $1964-1973$ & $1967-1976$ & $1970-1979$ & 8,2 & 6,7 \\
$\begin{array}{l}\text { Cohorte } \\
1962-1971\end{array}$ & $54-45$ & $1968-1977$ & $1974-1983$ & $1977-1986$ & $1980-1989$ & 9,3 & 8,8 \\
$\begin{array}{l}\text { Cohorte } \\
1972-1981\end{array}$ & $44-35$ & $1978-1987$ & $1984-1993$ & $1987-1996$ & $1990-1999$ & 9,8 & 9,7 \\
$\begin{array}{l}\text { Cohorte } \\
1982-1991\end{array}$ & $34-25$ & $1988-1997$ & $1994-2003$ & $1997-2006$ & $2000-2009$ & 10,8 & 10,6 \\
\hline
\end{tabular}

Fuente: elaboración propia con base en Torche (2010). Para reconstruir los años de entrada a los diferentes niveles educativos se consideran edades escolares típicas o ideales. El promedio de escolaridad se estima con base en datos del MMSI 2016.

Por su parte, la Educación Superior está conformada por más de tres mil instituciones públicas y privadas. El sector público presenta universidades federales, universidades públicas autónomas, universidades politécnicas, universidades interculturales, institutos tecnológicos federales y regionales, universidades tecnológicas, instituciones de investigación y posgrado, escuelas normales y otras instituciones. El sector privado incluye universidades, escuelas normales y otras instituciones de Educación Superior (ANUIES, 2018). Para el ciclo 2016-2017, el $67 \%$ de la matricula total se encuentra en instituciones públicas y el $33 \%$ en instituciones privadas, porcentajes que prácticamente no han variado en los últimos diez años (Mendoza Rojas, 2018). El proceso de ingreso a la Educación Superior varía por instituciones. Por ejemplo, algunas instituciones públicas solicitan el Examen Nacional de Ingreso a la Educación Superior (EXANI II) a cargo del CENEVAL y otras aplican sus propios exámenes de admisión (UNAM, UAM o IPN). En el caso de las instituciones privadas, el ingreso consiste en aplicar exámenes y/o el pago de inscripciones.

El cuadro 2 muestra la trayectoria educativa de las cuatro cohortes de nacimiento bajo estudio y además incluye el promedio de escolaridad de los hombres y las mujeres por cohorte.

Tomando como referencia las cohortes de mayor y menor edad al momento de la encuesta, se observa que la trayectoria educativa de la cohorte 19521961 se extiende aproximadamente desde el inicio de la década del sesenta hasta finales de los años setenta. Así, por ejemplo, los miembros de esta cohorte debieron experimentar la transición a la Educación Superior entre 1970 y 1979. Mientras que la trayectoria educativa de la cohorte 1982-1991 se inicia a finales de los años ochenta y sus miembros debieron experimentar la transición al nivel superior de educación a partir del año 2000.

A simple vista se destaca un incremento en el promedio de escolaridad de los hombres y, más específicamente, de las mujeres a través de las sucesivas 
cohortes de nacimiento. Además, tienden a reducirse gradualmente las brechas de género. Por ejemplo, el promedio de escolaridad pasó de 8,2 en la cohorte 1952-1961 a 10,8 en la cohorte 1982-1991 para los hombres, y de 6,7 en la cohorte 1952-1961 a 10,6 en la cohorte 1982-1991 para las mujeres. El promedio de escolaridad de los hombres y de las mujeres de la cohorte más joven (1982-1991) corresponde al primer año en la Educación Media Superior. El incremento generalizado en el promedio de escolaridad de la población se debe principalmente a la expansión de la cobertura en la Educación Básica durante la segunda mitad del siglo xx.

Este contexto abre un conjunto de interrogantes sobre la movilidad educativa absoluta: ¿qué efecto tiene el cambio estructural sobre las oportunidades absolutas de movilidad educativa intergeneracional?, ¿las oportunidades de absolutas movilidad educativa intergeneracional difieren entre los hombres y las mujeres a lo largo del tiempo? y, por último, ¿se observan cambios en la intensidad de la movilidad educativa intergeneracional absoluta entre los hombres y las mujeres pertenecientes a las cohortes más jóvenes?

El cuadro 3 presenta el panorama a nivel nacional, con la distribución de los encuestados por sexo y cohortes de nacimiento según la posición de origen y destino educativo. Específicamente, sobresalen tres grandes tendencias. Primero, a lo largo del tiempo disminuye la proporción de hombres y mujeres sin escolaridad y con Primaria en comparación con sus orígenes educativos. Así, por ejemplo, en la cohorte 1982-1991 los porcentajes en la categoría sin escolaridad pasaron de $8,2 \%$ en los orígenes a $0,7 \%$ en los destinos para los hombres, y de $8,8 \%$ en los orígenes a $1,0 \%$ en los destinos para las mujeres. Al respecto, la expansión de la cobertura educativa produjo una marcada reducción de la población sin acceso a la educación formal. Según datos de la Encuesta Intercensal 2015 del INEGI, el porcentaje de la población de 15 años y más que no sabe leer y escribir pasó de $25,8 \%$ en 1970 a $5,5 \%$ en 2015 (INEGI, 2015). ${ }^{9}$

Segundo, a lo largo del tiempo se incrementa la proporción de hombres y mujeres con Educación Secundaria y Media Superior en comparación con sus orígenes educativos. Por ejemplo, en la cohorte 1982-1991 los porcentajes en el nivel medio superior de educación pasaron de $10,7 \%$ en los orígenes a $24,5 \%$ en los destinos para los hombres, y de 9,0\% en los orígenes a 24,5\% en los destinos para las mujeres. Además, cabe señalar que la brecha de género en la Educación Media Superior se ha reducido considerablemente a lo largo del tiempo. En este sentido, en la cohorte más joven (1982-1991) la proporción de hombres y mujeres con Educación Media Superior es idéntica, como se menciona, representa el 24,5\%.

Tercero, a lo largo del tiempo se incrementa la proporción de hombres y mujeres con Educación Superior en comparación con sus orígenes educativos.

9. El porcentaje de la población de 15 años y más que no sabe leer y escribir varía por grandes grupos de edad ( $1,2 \%$ en el grupo de 15 a 29 años y 32,2 \% en el grupo de 75 años y más), y por entidad federativa (1,5\% en la Ciudad de México y 14,8 \% en Chiapas) (INEGI, 2015). 
Cuadro 3. Totales marginales de orígenes y destinos educativos por sexo y cohortes de nacimiento (en \%). Índice de disimilitud (ID).

\begin{tabular}{|c|c|c|c|c|c|c|c|c|c|c|c|c|c|}
\hline & & \multicolumn{3}{|c|}{ Cohorte 1952-1961 } & \multicolumn{3}{|c|}{ Cohorte 1962-1971 } & \multicolumn{3}{|c|}{ Cohorte 1972-1981 } & \multicolumn{3}{|c|}{ Cohorte 1982-1991 } \\
\hline & & Orígenes & Destinos & ID & Orígenes & Destinos & ID & Orígenes & Destinos & ID & Orígenes & Destinos & ID \\
\hline \multirow[t]{7}{*}{ Hombres } & Sin escolaridad & 36,0 & 6,5 & 41,3 & 25,1 & 3,2 & 49,4 & 15,7 & 1,8 & 44,9 & 8,2 & 0,7 & 32,7 \\
\hline & Primaria incompleta & 29,0 & 22,1 & & 30,3 & 11,3 & & 24,6 & 9,7 & & 16,2 & 6,1 & \\
\hline & Primaria completa & 21,6 & 16,7 & & 25,1 & 16,7 & & 28,7 & 12,7 & & 23,3 & 8,2 & \\
\hline & Secundaria & 6,8 & 20,8 & & 9,5 & 30,7 & & 15,0 & 33,8 & & 24,4 & 30,7 & \\
\hline & EMS & 1,9 & 10,9 & & 4,1 & 17,0 & & 6,5 & 19,5 & & 10,7 & 24,5 & \\
\hline & Superior & 4,7 & 23,0 & & 5,9 & 21,2 & & 9,4 & 22,6 & & 17,2 & 29,7 & \\
\hline & Total & $\begin{array}{r}100,0 \\
(1.551)\end{array}$ & $\begin{array}{r}100,0 \\
(1.551)\end{array}$ & & $\begin{array}{r}100,0 \\
(2.500)\end{array}$ & $\begin{array}{r}100,0 \\
(2.500)\end{array}$ & & $\begin{array}{r}100,0 \\
(3.101)\end{array}$ & $\begin{array}{r}100,0 \\
(3.101)\end{array}$ & & $\begin{array}{r}100,0 \\
(3.174)\end{array}$ & $\begin{array}{r}100,0 \\
(3.174)\end{array}$ & \\
\hline \multirow[t]{7}{*}{ Mujeres } & Sin escolaridad & 33,7 & 9,4 & 35,4 & 26,6 & 4,9 & 47,5 & 16,7 & 2,5 & 50,6 & 8,8 & 1,0 & 37,2 \\
\hline & Primaria incompleta & 34,6 & 23,5 & & 33,5 & 14,1 & & 29,3 & 7,2 & & 20,4 & 3,9 & \\
\hline & Primaria completa & 21,3 & 25,7 & & 24,9 & 18,5 & & 26,9 & 12,6 & & 22,9 & 9,9 & \\
\hline & Secundaria & 5,2 & 24,7 & & 8,1 & 37,0 & & 12,8 & 44,1 & & 26,0 & 33,7 & \\
\hline & EMS & 2,2 & 6,5 & & 2,7 & 11,1 & & 5,2 & 13,9 & & 9,0 & 24,5 & \\
\hline & Superior & 3,0 & 10,2 & & 4,2 & 14,5 & & 9,1 & 19,8 & & 13,0 & 27,0 & \\
\hline & Total & $\begin{array}{r}100,0 \\
(2.221)\end{array}$ & $\begin{array}{r}100,0 \\
(2.221)\end{array}$ & & $\begin{array}{r}100,0 \\
(3.404)\end{array}$ & $\begin{array}{r}100,0 \\
(3.404)\end{array}$ & & $\begin{array}{r}100,0 \\
(4.501)\end{array}$ & $\begin{array}{r}100,0 \\
(4.501)\end{array}$ & & $\begin{array}{r}100,0 \\
(3.930)\end{array}$ & $\begin{array}{r}100,0 \\
(3.930)\end{array}$ & \\
\hline
\end{tabular}

Fuente: elaboración propia con base en datos del MMSI 2016.

Por ejemplo, en la cohorte 1982-1991 el porcentaje con Educación Superior pasó de $17,2 \%$ en los orígenes a $29,7 \%$ en los destinos para los hombres, y de $13,0 \%$ en los orígenes a 27,0 \% en los destinos para las mujeres. Cabe destacar que la proporción de mujeres que logra ingresar al nivel superior de educación se incrementa de forma constante en el tiempo: de 10,2 \% en la cohorte 19521961 a 27,0 \% en la cohorte 1982-1991. Aunque la proporción de mujeres en la Educación Superior se incrementó considerablemente en las últimas décadas, todavía existe una segregación por tipo de carrera en comparación con los hombres. En este sentido, los resultados de la investigación realizada por de Garay y Valle Díaz Muñoz (2012) sobre presencia de las mujeres en la Educación Superior en México indican que

A pesar de los avances, la tendencia refleja que la mujer continúa participando más en unas áreas académicas y carreras profesionales de servicios culturalmente asociadas al género femenino como la enfermería, nutrición, humanidades y ciencias sociales, mientras que las áreas de las ingenierías y las ciencias exactas siguen siendo espacios profesionales asociados a los hombres (de Garay y Valle Díaz Muñoz, 2012: 28).

El cuadro 3 también incluye el índice de disimilitud (ID) que suele interpretarse como medida de movilidad estructural. En este sentido, ¿̨qué cambios se observan respecto a la magnitud de la movilidad educativa estructural para 
Cuadro 4. Medidas absolutas de movilidad educativa intergeneracional por sexo y cohorte de nacimiento (en \%).

\begin{tabular}{llcccc}
\hline & & \multicolumn{3}{c}{ Cohortes de nacimiento } \\
\cline { 3 - 6 } & Tipo de movilidad & $\mathbf{1 9 5 2 - 1 9 6 1}$ & $\mathbf{1 9 6 2 - 1 9 7 1}$ & $\mathbf{1 9 7 2 - 1 9 8 1}$ & $\mathbf{1 9 8 2 - 1 9 9 1}$ \\
\hline Hombres & Movilidad ascendente & 76,7 & 77,4 & 70,6 & 62,0 \\
& Inmovilidad o herencia & 19,3 & 18,2 & 22,5 & 28,9 \\
& Movilidad descendente & 4,0 & 4,4 & 6,9 & 9,1 \\
\hline Mujeres & Movilidad ascendente & 66,9 & 74,7 & 72,1 & 67,9 \\
& Inmovilidad o herencia & 25,7 & 19,1 & 21,4 & 24,4 \\
& Movilidad descendente & 7,4 & 6,2 & 6,5 & 7,7 \\
\hline
\end{tabular}

Fuente: elaboración propia con base en datos del MMSI 2016.

los hombres y las mujeres a lo largo del tiempo? Si se toma como categoría de contraste a la cohorte de mayor edad en la encuesta (1952-1961), se advierte un incremento de la movilidad estructural en las cohortes intermedias. Es decir, producto de los cambios globales en el nivel educativo entre generaciones, aproximadamente 5 de cada 10 hombres de la cohorte 1962-1971 (ID $=49,4 \%)$ y 5 de cada 10 mujeres de la cohorte 1972-1981 (ID = 50,6\%) cambiaron su nivel educativo con respecto a sus orígenes. En cambio, en la cohorte 1982-1991 disminuye la magnitud de la movilidad estructural: el ID se ubica en $32,7 \%$ entre los hombres y $37,2 \%$ entre las mujeres. Es decir, en la cohorte 1982-1991 se restringe el volumen de movilidad intergeneracional que obedece al cambio en las distribuciones de orígenes y destinos educativos, en mayor medida para los hombres. ${ }^{10}$

Para finalizar esta sección del artículo, el cuadro 4 muestra un conjunto de medidas absolutas que dan cuenta de la intensidad y la "dirección» de la movilidad educativa intergeneracional: 1) inmovilidad o herencia, 2) movilidad ascendente y 3) movilidad descendente.

En términos generales, predomina la movilidad ascendente frente a la inmovilidad y la movilidad descendente tanto para hombres y mujeres en las cuatro cohortes de nacimiento. Si bien las mediadas absolutas de movilidad educativa ascendente son altas, deben tomarse con recaudo por tres razones. Primero, el incremento en los niveles de escolaridad se ha dado en un contexto caracterizado por cuestionamientos a la calidad educativa. Segundo, la desigualdad en la calidad educativa se asocia a la segmentación institucional. Tercero, las oportunidades educativas se encuentran condicionadas por el origen social de las personas (Solís, 2018).

10. Esto también puede deberse a un efecto de «freno natural» de la movilidad debido a que más del 50,0\% de los hombres y las mujeres de la cohorte 1982-1991 alcanzaron la Educación Media Superior y Superior — 54,2 \% hombres y 51,5 \% mujeres. Como la Educación Media Superior y Superior representan las categorías extremas de la distribución, se limita la movilidad mínima permitida por las distribuciones totales de orígenes y destinos educativos. 
Cabe señalar que la magnitud de la movilidad educativa ascendente presenta algunas diferencias entre los hombres y las mujeres a través de las cohortes de nacimiento. Para los hombres la movilidad ascendente se reduce de 77,4\% en la cohorte 1962-1971 a 62,0 \% en la cohorte más joven (1982-1991) disminuye alrededor de 15 puntos porcentuales. En cambio, para las mujeres la magnitud de la movilidad ascendente se mantiene prácticamente constante en las cohortes intermedias (74,7 \% en la cohorte $1962-1971$ y $72,1 \%$ en la cohorte 1972-1981) y, posteriormente, se reduce a $67,9 \%$ en la cohorte 1982-1991. Entre la cohorte 1962-1971 y la cohorte 1982-1991 disminuye cerca de 7 puntos porcentuales.

A pesar del predominio de la movilidad educativa ascendente, en la cohorte más joven (1982-1991) casi 4 de cada 10 hombres no experimentaron movilidad o tuvieron una movilidad descendente. En este caso los porcentajes de inmovilidad y movilidad descendente son $28,9 \%$ y $9,1 \%$, respectivamente. Mientras que para las mujeres los porcentajes respectivos son $24,4 \%$ y $7,7 \%$.

\section{Barreras a la movilidad educativa intergeneracional}

Las medidas absolutas de movilidad educativa son descriptivas y

...dependen de dos factores: por una parte, los marginales de origen y destino que cambian a consecuencia de la expansión educacional; por otra, la asociación neta entre educación de padres e hijos (Torche, 2010: 85).

A continuación, el análisis se concentra en la medición de la movilidad educativa relativa mediante la estimación de modelos log lineales que, una vez controladas las diferencias en las distribuciones marginales de la tabla, permiten captar la asociación neta entre orígenes y destinos a través de las odds ratio (Erikson y Goldthorpe, 1992; Breen, 2004).

\section{Independencia condicional}

$$
\lambda+\lambda_{i}^{0}+\lambda_{j}^{D}+\lambda_{k}^{C}+\lambda_{i k}^{O C}+\lambda_{j k}^{D C}
$$

El modelo de independencia condicional asume que las frecuencias esperadas en cada una de celdas de la tabla de movilidad educativa intergeneracional dependen de los efectos marginales $\lambda_{i}^{o} \lambda_{j}^{D} \lambda_{k}^{C}$ (origen educativo, destino educativo y cohorte de nacimiento) y del cambio en los marginales entre las cohortes de nacimiento $\lambda_{i k}^{O C} \lambda_{j k}^{D C}$, pero no de las interacciones entre orígenes y destinos educativos. Es decir, asume que no hay asociación entre orígenes y destinos educativos. En este sentido, «este modelo supone que el origen social y el destino educacional son independientes en cada cohorte de nacimiento. Por consiguiente, expresa la hipótesis de una completa igualdad de oportunidades educacionales» (Vallet, 2016: 266). 
Asociación homogénea

$$
\operatorname{In} \mu_{i j k}=\lambda+\lambda_{i}^{o}+\lambda_{j}^{D}+\lambda_{i k}^{O C}+\lambda_{j k}^{D C}+\lambda_{i j}^{O C}
$$

El modelo de asociación homogénea incluye los efectos de la asociación entre orígenes y destinos educativos, pero asume que los mismos son constantes a lo largo de las cohortes de nacimiento. En este caso, se remplaza el parámetro que refiere a la interacción entre orígenes y destinos educativos por los parámetros de cruces $(\mathrm{Cr} 1, \mathrm{Cr} 2, \mathrm{Cr} 3$ y $\mathrm{Cr} 4)$.

Asociación condicional ${ }^{11}$

$$
\operatorname{In} \mu_{i j k}=\lambda+\lambda_{i}^{o}+\lambda_{j}^{D}+\lambda_{k}^{C}+\lambda_{i k}^{O C}+\lambda_{j k}^{D C}+\lambda_{i j}^{O D}+\lambda_{i j k}^{O D C}
$$

El modelo de asociación condicional postula que la asociación entre orígenes y destinos educativos varía entre las cohortes de nacimiento, incorporando un parámetro adicional que captura dicha variación $-\lambda_{i k}^{O C}$. Este parámetro se remplaza por los parámetros que capturan la interacción entre cada uno de los cruces (Cr1, Cr2, Cr3 y Cr4) y las cohortes de nacimiento. Este modelo permite evaluar "la variación de los parámetros de cruce a través de las cohortes" (Torche, 2010: 91).

En el análisis log lineal es importante responder la siguiente pregunta: ¿qué tan apropiadamente los modelos log lineales ajustan las frecuencias observadas en las tablas? Para responder a esta pregunta se utilizan tres medidas: la $G^{2}$ (deviance), el BIC (bayesian information criterion) y el índice de disimilitud $(\Delta)$ (Powers y Xie, 2000). La G ${ }^{2}$ se calcula como

$$
\sum_{i=1}^{1} \sum_{J=1}^{J} f_{i j} \operatorname{In}\left(\frac{f_{i j}}{F_{i j}}\right)
$$

donde $f_{i j}$ corresponde a las frecuencias observadas en la tabla de movilidad. La $\mathrm{G}^{2}$ se aproxima a la distribución X cuadrada y su valor depende del tamaño de la muestra. El BIC se calcula como $\mathrm{G}^{2}-g l(\ln (\mathrm{n}))$. Es decir, el valor de $\mathrm{G}^{2}$ que se estima en el modelo menos el producto de los grados de libertad por el logaritmo de $n$ (total de la muestra). A menor valor del BIC, mejor es el ajuste del modelo. El tercer criterio para evaluar la bondad de ajuste es el índice de disimilitud $(\Delta)$ y se obtiene mediante el siguiente cálculo:

$$
\sum_{i=1}^{I} \sum_{j=1}^{J}\left|\frac{f_{i j}-F_{i j}}{2 n}\right| .
$$

El valor del índice de disimilitud expresado en porcentaje indica la proporción de casos que deberían cambiar de celda para que las frecuencias

11. Se bloquea la diagonal de inmovilidad/herencia educativa mediante un parámetro adicional. 
Cuadro 5. Ajuste modelos log lineales.

\begin{tabular}{|c|c|c|c|c|c|c|c|}
\hline & Modelos & $\mathrm{G}^{2}$ (deviance) & $g l$ & Prob $>G^{2}$ & BIC & $\begin{array}{c}\text { Índice de } \\
\text { disimilitud }(\Delta)\end{array}$ & $\begin{array}{l}\text { Asociación } \\
\text { explicada }\end{array}$ \\
\hline \multirow[t]{3}{*}{ Hombres } & Independencia condicional & $4.392,8$ & 100 & 0,000 & $3.468,5$ & 24,1 & ----- \\
\hline & Asociación homogénea o fluidez constante & $1.173,3$ & 95 & 0,000 & 295,2 & 12,7 & 73,3 \\
\hline & Asociación condicional & 497,4 & 76 & 0,000 & $-205,0$ & 7,1 & 88,7 \\
\hline \multirow[t]{3}{*}{ Mujeres } & Independencia condicional & $5.187,3$ & 100 & 0,000 & $4.232,2$ & 21,4 & ------ \\
\hline & Asociación homogénea o fluidez constante & $1.399,3$ & 95 & 0,000 & 491,9 & 11,9 & 73,0 \\
\hline & Asociación condicional & 615,4 & 76 & 0,000 & $-110,5$ & 7,3 & 88,1 \\
\hline \multirow{6}{*}{$\begin{array}{l}\text { Contraste } \\
\text { de modelos }\end{array}$} & \multirow{3}{*}{\multicolumn{2}{|c|}{$\begin{array}{l}\text { Hombres: asociación homogénea vs. asociación } \\
\text { condicional }\end{array}$}} & \multicolumn{5}{|c|}{ Diferencia $\mathrm{G}^{2}(1.173,3-497,4)=675,9$} \\
\hline & & & \multicolumn{5}{|c|}{ Diferencia $g l(95-76)=19$} \\
\hline & & & \multicolumn{5}{|c|}{$p>0,000$} \\
\hline & \multirow{3}{*}{\multicolumn{2}{|c|}{$\begin{array}{l}\text { Mujeres: asociación homogénea vs. independencia } \\
\text { condicional }\end{array}$}} & \multicolumn{5}{|c|}{ Diferencia G ${ }^{2}(1.399,3-615,4)=783,9$} \\
\hline & & & \multicolumn{5}{|c|}{ Diferencia $g /(95-76)=19$} \\
\hline & & & \multicolumn{5}{|c|}{$p>0,000$} \\
\hline
\end{tabular}

Fuente: elaboración propia con base en datos del MMSI 2016.

estimadas por el modelo coincidan con las frecuencias observadas. Cuanto menor sea el valor del índice de disimilitud, más ajustado a los datos es el modelo y, por tanto, preferible (López-Roldán y Fachelli, 2015). Por ejemplo, Solís (2016b) utiliza modelos log lineales para analizar la movilidad relativa de clase en México. El índice de disimilitud de los modelos oscila entre $4,9 \%$ y $4,1 \%$ para los hombres y entre $7,3 \%$ y $6,9 \%$ para las mujeres. Por último, la evaluación y elección de un modelo también «es guiada por la propiedad aditiva de la $\mathrm{G}^{2}$ : la diferencia entre dos $\mathrm{G}^{2}$ con $g l_{1}$ y $g l_{2}$ grados de libertad se distribuye como la $\mathrm{X}^{2}$ con $g l_{1}-g l_{2}$ grados de libertad» (Hout, 1983: 42). Este principio se aplica con el propósito de contrastar los diferentes modelos log lineales y, posteriormente, calcular los valores de los diferentes efectos o parámetros para conocer su importancia ${ }^{12}$ (López-Roldán y Fachelli, 2015).

El modelo de independencia condicional se utiliza como base de comparación para evaluar el ajuste de los otros modelos log lineales estimados. La $\mathrm{G}^{2}$ del modelo para los hombres es de 4.392,8 y de 5.187,3 para las mujeres, ambas resultan estadísticamente significativas con una $\mathrm{p}<0,05$. Asimismo, según el índice de disimilitud $24,1 \%$ de los casos para los hombres y $21,4 \%$ de los casos para las mujeres deberían ser cambiados de celda para que la distribución de frecuencias estimadas coincida con la observada. En síntesis, las medidas de bondad de ajuste del modelo de independencia condicional indican que debe rechazarse la hipótesis de la igualdad de oportunidades educativas.

12. Las tres medidas $\left(\mathrm{G}^{2}\right.$, BIC y $\left.\Delta\right)$ presentan potencialidades y limitaciones para evaluar la bondad de ajuste de los modelos log lineales (para un mayor detalle, véase Powers y Xie, 2000). 
En el modelo de asociación homogénea se produce un avance tanto para los hombres como para las mujeres. En ambos casos la $\mathrm{G}^{2}$ y el BIC disminuyen considerablemente $\left(\mathrm{G}^{2}=1.173,3\right.$ y $\mathrm{BIC}=295,2$ para los hombres y $\mathrm{G}^{2}$ $=1.399,3$ y $\mathrm{BIC}=491,9$ para las mujeres), pero todavía no se logra un buen ajuste. Según el índice de disimilitud, el modelo falla al asignar correctamente en las tablas $12,7 \%$ de los casos para los hombres y $11,9 \%$ de los casos para las mujeres. La asociación explicada bajo independencia estadística es 73,3\% para los hombres y 73,0 \% para las mujeres.

El modelo de asociación condicional mejora considerablemente el ajuste respecto del modelo anterior tanto para los hombres como para las mujeres, según las tres medidas consideradas: $\mathrm{G}^{2}=497,4$ y $\mathrm{BIC}=-205,0$ para los hombres y $\mathrm{G}^{2}=615,4$ y $\mathrm{BIC}=-110,5$ para las mujeres -el $\mathrm{BIC}$ toma valores negativos. El índice de disimilitud se reduce y se ubica en $7,1 \%$ para los hombres y 7,3 \% para las mujeres. La asociación explicada bajo independencia estadística se incrementa: $88,7 \%$ para los hombres y $88,1 \%$ para las mujeres. Además, el cambio de la $\mathrm{G}^{2}$ al comparar el modelo de asociación homogénea con el modelo de asociación condicional es significativo. En este sentido, se prefiere el modelo de asociación condicional por sobre el modelo de asociación homogénea. ${ }^{13} \mathrm{El}$ ajuste que presenta el modelo de asociación condicional indica que existe un cambio significativo en las barreras a la movilidad educativa tanto para los hombres como para las mujeres a través del tiempo.

La cuantificación del modelo de asociación condicional a través de la estimación de los parámetros de cruce permite analizar los cambios de las barreras a la movilidad educativa intergeneracional para los hombres y las mujeres a través de las cohortes de nacimiento (gráficos 1 y 2). ${ }^{14}$

La primera y la segunda barrera a la movilidad (Cr1 y Cr2), que registran la dificultad de acceder y de finalizar la Primaria para los hombres de orígenes educativos sin escolaridad y con Primaria incompleta, disminuyen gradualmente a través de las cuatro cohortes de nacimiento. En cambio, las mujeres de orígenes educativos sin escolaridad y con Primaria incompleta enfrentan grandes dificultades relativas para acceder y para finalizar la Educación Primaria. Por ejemplo, la barrera Cr1 sin escolaridad/Primaria incompleta se incrementa a través de las cohortes de nacimiento para las mujeres: el coeficiente $-1,58$ en su versión exponencial $\left(\exp ^{-1,58}=0,21\right)$ indica que para las mujeres de la cohorte 1982-1991 la oportunidad de cruzar esta barrera

13. Ahora bien, el modelo de asociación condicional es menos parsimonioso que el modelo de asociación homogénea o fluidez constante porque utiliza más parámetros. Al respecto, Powers y Xie (2000) señalan que «siempre hay una tensión entre la precisión y la parsimonia en un modelo estadístico. Por parsimonia, comúnmente entendemos modelos estadísticos con pocos parámetros. Por precisión, entendemos la habilidad para reproducir los datos, medida por los estadísticos de bondad de ajuste. Aunque tanto la precisión como la parsimonia son propiedades deseables en un modelo estadístico, una se logra solo a expensas de la otra» (Powers y Xie, 2000: 22).

14. Los parámetros de cruce son negativos porque reflejan las barreras a la movilidad educativa intergeneracional. En este caso, se multiplican por -1 para facilitar la interpretación: en los gráficos las barras más altas representan las barreras más difíciles de cruzar (Torche, 2010). 
Gráfico 1. Coeficientes de los parámetros de cruce (b), multiplicados por -1 para facilitar la interpretación. Hombres miembros de las cuatro cohortes.

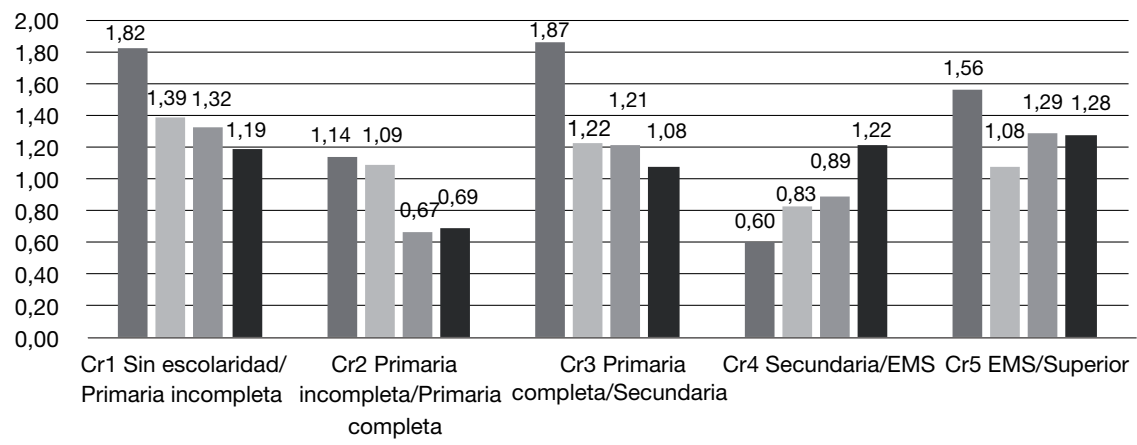

Cohorte 1952-1961_ Cohorte 1962-1971

Cohorte 1972-1981

Cohorte 1982-1991

Nota: todos los parámetros son significativos $p>0,005$.

Fuente: elaboración propia con base en datos del MMSI 2016

Gráfico 2. Coeficientes de los parámetros de cruce (b), multiplicados por -1 para facilitar la interpretación. Mujeres miembros de las cuatro cohortes.

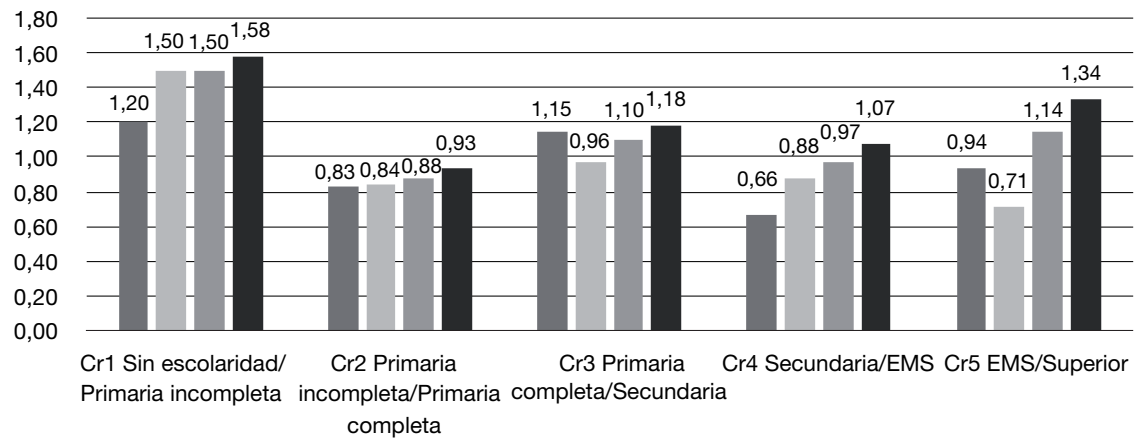

Cohorte 1952-1961 Cohorte 1962-1971_ Cohorte 1972-1981

Cohorte 1982-1991

Nota: todos los parámetros son significativos $p>0,005$.

Fuente: elaboración propia con base en datos del MMSI 2016.

es $79 \%$ menor con relación a la inmovilidad o herencia educativa - no experimentar movilidad.

La barrera que captura la dificultad de acceder a la Secundaria para los hombres que provienen de orígenes con Educación Primaria completa $(\mathrm{Cr} 3)$ disminuye a través de las cuatro cohortes de nacimiento: el coeficiente $\mathrm{Cr} 3$ pasa de -1,87 en la cohorte 1952-1961 a -1,08 en la cohorte 1982-1991. Por el contrario, para las mujeres de orígenes con Educación Primaria completa la 
barrera que restringe el acceso a la Secundaria disminuye en la cohorte 19621971 y, posteriormente, se incrementa en las cohortes 1972-1981 y 1982-1991.

La barrera en la parte media de la distribución educativa - Secundaria / EMS - (Cr4) se incrementa a través de las cohortes de nacimiento tanto para los hombres como para las mujeres de orígenes con Educación Secundaria. Sin embargo, cabe señalar que en la cohorte más joven (cohorte 1982-1991) las mujeres enfrentan una menor dificultad para acceder al nivel medio superior de educación que los hombres: mujeres $\mathrm{Cr} 4=-1,07$ vs. hombres $\mathrm{Cr} 4=-1,22$.

La barrera en la parte alta de la distribución educativa -EMS / Superior(Cr5) también se incrementa a través de las cohortes de nacimiento tanto para los hombres como para las mujeres de orígenes con Educación Media Superior. Si se compara con la cohorte de mayor edad (1952-1961), la magnitud de la barrera Cr5 disminuye en la cohorte 1962-1971, probablemente beneficiada del final de la fase expansiva de la Educación Superior que comprende los años cincuenta hasta el inicio de los ochenta (Rodríguez Gómez, 1999), ${ }^{15}$ y posteriormente se incrementa en las dos cohortes sucesivas 1972-1981 y 1982-1991. Por ejemplo, la versión exponencial de los coeficientes $\left(\exp ^{-1,25}=0,29\right.$ para los hombres y $\exp ^{-1,34}=0,26$ para las mujeres) indica que la chance de acceder al nivel superior es $71 \%$ menor para los hombres y $74 \%$ menor para las mujeres de la cohorte 1982-1991 en relación con la inmovilidad o herencia educativa.

Los resultados indican que las oportunidades educativas en los niveles básicos (Primaria y Secundaria) con respecto al efecto del origen tienden a ser más igualitarias para los hombres que para las mujeres a lo largo del tiempo. Es decir, las mujeres de origen sin escolaridad y con Primaria tienen una mayor persistencia en esos niveles que los hombres del mismo origen. Si bien la proporción de mujeres de origen sin escolaridad y con primaria completa e incompleta disminuye considerablemente — véase el cuadro 3-, "las significativas barreras a la movilidad que enfrentan sugieren el riesgo de que este grupo se transforme en un sector altamente marginado y con mínimas oportunidades de ascenso educacional» (Torche, 2010: 88).

El efecto del origen se incrementa en el acceso a la Educación Media Superior y Superior para los hombres y las mujeres en el transcurso del tiempo, principalmente en la cohorte más joven. En otras palabras, a pesar de que la proporción de hombres y mujeres que accede a la Educación Media Superior y Superior tiende a incrementarse en el transcurso del tiempo — véase el cuadro 3 -, en la competencia por los lugares disponibles en esos niveles educativos el origen social constituye un factor cada vez más determinante (Torche, 2010; Solís, 2013; 2014; Blanco, 2017). Al respecto, los resultados de investigaciones recientes sobre trayectorias educativas en México indican que, en la transición a la Educación Media Superior y Superior, «se activa una suerte de «acaparamiento de oportunidades» por parte de los estratos sociales más privilegiados, generando alta desigualdad de oportunidades» (Solís, 2014: 73).

15. Los hombres y las mujeres de la cohorte 1962-1971 debieron experimentar la transición a la Educación Superior entre 1980 y 1989 —véase el cuadro 2. 
Cuadro 6. Oportunidades de acceder a la Educación Media Superior y Superior para hombres y mujeres de la cohorte 1982-1991 de origen social sin escolaridad (en la métrica de las odds ratio).

\begin{tabular}{lccc}
\hline & \multirow{2}{*}{$\begin{array}{c}\text { Cohorte de } \\
\text { Sexo }\end{array}$} & \multicolumn{2}{c}{ Oportunidades de acceder a } \\
\cline { 3 - 4 } nacimiento & Educación Media Superior & Educación Superior \\
\hline Hombres & $1982-1991$ & $\exp ^{(-1,19+-0,69+-1,08+-1,22)}=0,015$ & $\exp (-1,19+-0,69+-1,08+-1,22+-1,28)=0,004$ \\
Mujeres & & $\exp (-1,58+-0,93+-1,18+-1,07)=0,009$ & $\exp (-1,58+-0,93+-1,18+-1,07+-1,34)=0,002$ \\
\hline
\end{tabular}

Fuente: elaboración propia con base en datos del MMSI 2016.

Hasta aquí el análisis se ha concentrado en la movilidad intergeneracional entre niveles educativos adyacentes que refleja pautas de «movilidad de corta distancia». Ahora bien, la probabilidad de movilidad entre niveles educativos no adyacentes se calcula a través de la suma de las barreras entre los niveles adyacentes que los separan (Torche, 2010). Por ejemplo, para que una persona de origen educativo sin escolaridad alcance el nivel superior tiene que cruzar 5 barreras: sin escolaridad y Primaria incompleta (Cr1); Primaria incompleta y Primaria completa $(\mathrm{Cr} 2)$; Primaria completa y Secundaria (Cr3); Secundaria y EMS (Cr4), y EMS y Superior (Cr5). En este caso, la expresión [exp (-Cr1 $+-\mathrm{Cr} 2+-\mathrm{Cr} 3+-\mathrm{Cr} 4+-\mathrm{Cr} 5)]$ da cuenta de la suma de los coeficientes de cruce en su versión exponencial. Dado que el efecto del origen en el acceso a la Educación Media Superior y Superior tiende a incrementarse a través de las cohortes de nacimiento, cabría preguntarse: ¿qué oportunidades tienen los hombres y las mujeres de la cohorte 1982-1991 que provienen del origen sin escolaridad de avanzar hacia los niveles educativos más altos? Es decir, ¿qué chances tienen de experimentar trayectorias de movilidad ascendente de larga distancia?

Los hombres y las mujeres de la cohorte 1982-1991 que provienen del origen social sin escolaridad tienen escasas oportunidades de acceder a la Educación Media Superior y Superior: las odds de alcanzar la Educación Media Superior y superior con respecto a permanecer en el nivel educativo de origen - sin escolaridad - tan solo representan 0,015 y 0,004 para los hombres y 0,009 y 0,002 para las mujeres, respectivamente. A nivel internacional, en la compilación de estudios de Blossfeld y Shavit (1993), los autores analizaron el proceso de logro educativo en trece países desarrollados. ${ }^{16} \mathrm{~A}$ pesar de la expansión educativa, evidenciaron una estabilidad de las desigualdades socioeconómicas en las oportunidades educativas en el tiempo para once de los trece países, con excepción de Suecia y Holanda. Con base en los hallazgos de investigación, Blossfeld y Shavit (1993) plantearon la hipótesis de «la desigualdad persistente» en logros educativos (Blossfeld y Shavit, 1993). Sin embargo, estudios recientes apoyados en grandes bases de datos y estrategias metodológicas sofisticadas cuestionaron fuertemente esta hipótesis. Por ejemplo, Tam y Ganzeboom (2009) se preguntan: ¿la desigualdad persistente es un espejismo?

16. El estudio incluye principalmente países de Europa. Además, incorpora Estados Unidos, Israel, Taiwán y Japón. 
Señalan que esta hipótesis es una generalización sociológica provocativa (Tam y Ganzeboom, 2009). Por su parte, Breen et al. (2009) reportaron una disminución generalizada de la desigualdad educativa entre personas de diferentes orígenes sociales en ocho países europeos. Entre sus argumentos teóricos, destacan que los efectos primarios y secundarios cambiaron significantemente en la segunda mitad del siglo xx y, de esta manera, se espera una menor influencia de los orígenes de clase sobre el logro educativo; en particular, los hijos de la clase obrera son quienes deberían haber mejorado considerablemente su posición relativa (Breen et al., 2009).

En México los resultados indican que, durante las últimas décadas del siglo $\mathrm{XX}$ y principios del siglo XXI, se restringen las oportunidades de experimentar movilidad educativa ascendente de larga distancia para las personas de orígenes sociales desfavorecidos. Esto coincide con los hallazgos de investigaciones sobre movilidad de clase, que también reportan un incremento en la rigidez del régimen de estratificación social y una persistencia de las distancias sociales entre las clases a partir de la década del ochenta (Cortés et al., 2007; Solís, 2007; Torche, 2010; Solís, 2016b).

\section{Repaso de resultados y discusión}

En este artículo se analizaron las oportunidades absolutas y relativas de movilidad educativa intergeneracional por sexo y cohortes de nacimiento en México. Para ello se utilizaron datos del Módulo de Movilidad Social Intergeneracional (MMSI) de 2016. A partir de tablas de doble entrada que contrastan los orígenes y los destinos educativos, se calcularon medidas absolutas de movilidad educativa intergeneracional por sexo y cohortes de nacimiento. Mediante la estimación de modelos log lineales se obtuvieron medidas relativas con el propósito de evaluar los cambios en las barreras a la movilidad educativa intergeneracional para los hombres y las mujeres a través de las cohortes de nacimiento.

El panorama educativo general se caracteriza por un fuerte incremento en los niveles promedio de escolaridad de los hombres y de las mujeres a través de las cohortes de nacimiento. También se observa una reducción paulatina de las brechas de género en los niveles promedio de escolaridad. Así, por ejemplo, los hombres y las mujeres de la cohorte de nacimiento 1982-1991 tienen un promedio de escolaridad que corresponde al primer año en la Educación Media Superior.

Cuando se contrastan los orígenes y los destinos educativos por sexo y cohortes de nacimiento, se destacan tres grandes tendencias: 1) disminuye la proporción de hombres y mujeres sin escolaridad y con Primaria en comparación con sus orígenes educativos a través de las cohortes de nacimiento; 2) aumenta la proporción de hombres y mujeres que alcanzan la Secundaria y la Educación Media Superior en comparación con sus orígenes a través de las cohortes de nacimiento; y por último, 3) aumenta la proporción de hombres y mujeres con acceso a la Educación Superior en comparación con sus orígenes a través de las cohortes de nacimiento. La proporción de mujeres con acceso 
a la Educación Superior se incrementó casi 17 puntos porcentuales entre la cohorte 1952-1961 y la cohorte 1982-1991.

Dado los cambios globales en el nivel de escolaridad entre generaciones, se observa un marcado incremento de la movilidad estructural en las cohortes de nacimiento intermedias. En cambio, en la cohorte más joven (1982-1991) disminuye la magnitud de la movilidad estructural: de la movilidad educativa observada, representa el 32,7 \% entre los hombres y el 37,2 \% entre las mujeres.

Las medidas absolutas que refieren a la intensidad y a la dirección de la movilidad educativa indican que predomina la movilidad ascendente frente a la inmovilidad y a la movilidad descendente tanto para los hombres como para las mujeres en las cuatro cohortes de nacimiento bajo estudio. Entre las mujeres el flujo de movilidad ascendente tiende a incrementarse en las cohortes intermedias. A pesar del predominio de la movilidad educativa ascendente, en la cohorte 1982-1991 casi 4 de cada 10 hombres no experimentaron movilidad o tuvieron movilidad descendente, el 28,9\% y el 9,1\% respectivamente. Entre las mujeres de la cohorte 1982-1991, el 24,4 \% no experimentó movilidad y el $7,7 \%$ tuvo movilidad descendente con relación a sus orígenes educativos.

Las barreras que restringen las oportunidades de movilidad educativa intergeneracional cambian significativamente para los hombres y las mujeres a lo largo del tiempo. Para las mujeres se destaca un incremento de las barreras en los extremos de la distribución educativa que obstaculiza la salida desde los niveles educativos bajos (sin escolaridad y Primaria), así como el acceso a la Educación Media Superior y Superior. Para los hombres las barreras a la movilidad disminuyen en la parte baja de la distribución educativa, pero la influencia del origen en el acceso a la Educación Media Superior y Superior tendió a incrementarse a través del tiempo. Tanto para los hombres como para las mujeres la influencia del origen educativo en el acceso a la Educación Media Superior y Superior se intensifica en la cohorte más joven. Finalmente, los hombres y las mujeres de la cohorte más joven que provienen de orígenes educativos bajos enfrentan grandes dificultades relativas para avanzar hacia la Educación Media Superior y Superior, por lo que se restringen las oportunidades de experimentar una movilidad educativa ascendente de larga distancia.

Si bien los resultados del artículo no se contrastan con las hipótesis de movilidad social en países de industrialización tardía (Ishida, 2008), sugieren que, en el caso de México, se combinan altas tasas de movilidad absoluta producto de la expansión educativa durante la segunda mitad del siglo xx y un menor nivel de fluidez social en el acceso a la Educación Media Superior y Superior, particularmente en las cohortes más jóvenes. En este sentido, la expansión en la Educación Media Superior y Superior parece haber beneficiado principalmente a las personas de orígenes sociales altos, que, mediante el acaparamiento de oportunidades educativas, resguardan sus posiciones de privilegio en la estructura social.

Para mitigar los efectos del origen social sobre los patrones de movilidad educativa intergeneracional, resulta indispensable ampliar las oportunidades 
educativas en los grupos sociales más desfavorecidos (p. ej. mejorar la calidad en nivel básico y medio y ampliar cobertura en nivel medio superior y superior). Se requiere de programas que apunten a fortalecer el ingreso, permanencia y egreso de la Educación Media Superior y Superior para los jóvenes que provienen de familias con bajos recursos socioeconómicos. No debe perderse de vista que una alternativa para superar las desventajas asociadas al origen social familiar se da, en gran medida, a través de la educación. Para las personas de orígenes sociales desfavorecidos que no heredan recursos socioeconómicos y culturales, la educación puede constituir el canal principal de movilidad social ascendente. Para finalizar, la reforma 2019 a los artículos $3^{\circ}, 31^{\circ}$ y $73^{\circ}$ de la Constitución Política abre una agenda de investigación futura sobre las implicaciones de la obligatoriedad de la Educación Superior en los patrones de estratificación y movilidad social intergeneracional en México.

\section{Referencias bibliográficas}

Agresti, Alan (2007). An introduction to Categorical Data Analysis. Nueva Jersey: John Wiley \& Sons.

ANUIES (2018). Visión y acción 2030. Propuesta de la ANUIES para renovar la educación superior en México. México: Asociación Nacional de Universidades e Instituciones de Educación Superior (ANUIES).

Balán, Jorge; Browning, Harley L.; Jelin, Elizabeth (1977). El hombre en una sociedad en desarrollo. Movilidad social y geográfica en Monterrey. México: Fondo de Cultura Económica.

Blanco, Emilio (2017). «La desigualdad de oportunidades educativas en la Ciudad de México: persistencias y transformaciones». En: Solís, Patricio (coord.). Desigualdad, movilidad social y curso de vida en la Ciudad de México. México: El Colegio de México.

Blossfeld, Hans Peter; Shavit, Yossi (1993) (eds.). Persisting Inequality: Changing Educational Attainment in Thirteen Countries. Boulder: Westview Press.

Breen, Richard (2004) (ed.). Social Mobility in Europe. Oxford: Oxford University Press.

Breen, Richard; Jonsson, Jan O. (2005). «Inequality of Opportunity in Comparative Perspective: Recent research on educational attainment and social mobility». Annual Review of Sociology, 31, 223-244. $<$ https://doi.org/10.1146/annurev.soc.31.041304.122232>.

Breen, Richard; Luijkx, Ruud; Müller, Walter; Pollak, Reinhard (2009). «Nonpersistent Inequality in Educational Attainment: Evidence from Eight European Countries». American Journal of Sociology, 114, 1475-1521. $<$ https://doi.org/10.1086/595951>.

Breen, Richard; Mood, Carina; Jonsson, Jan O. (2016). «How much scope for a mobility paradox? The relationship between social and income mobility in Sweden». Sociological Science, 3, 39-60. $<$ https://doi.org/10.15195/v3.a3 >.

Campos Vázquez, Raymundo (2016). Promoviendo la Movilidad Social en México. Informe de Movilidad Social 2015. México DF: El Colegio de México.

CEEY (2012). Informe Movilidad Social en México 2013 Imagina tu futuro. México: Centro de Estudios Espinosa Yglesias, A. C. 
- (2018). El México del 2018. Movilidad social para el bienestar. México: Centro de Estudios Espinosa Yglesias, A. C.

COLMEX (2018). Desigualdades en México 2018. México, Ciudad de México: El Colegio de México - Red de Estudios sobre Desigualdades.

Contreras Suárez, Enrique (1978). Estratificación y movilidad social en la Ciudad de México. México: Instituto de Investigaciones Sociales-UNAM.

Cortés, Fernando; Escobar, Agustín; Solís, Patricio (2007). Cambio estructural y movilidad social en México. México: El Colegio de México.

ERIKson, Robert; Goldthorpe, John (1992). The constant flux: A study of class mobility in industrial societies. Oxford: Clarendon Press.

Garay, Adrián de; Valle Díaz Muñoz, Gabriela del (2012). «Una mirada a la presencia de las mujeres en la educación superior en México». Revista Iberoamericana de Educación Superior, 3 (6), 3-30. $<$ https://doi.org/10.22201/iisue.20072872e.2012.6>.

Glenn, Norval (2005). Cohort Analysis. Second Edition. Thousand Oaks: Sage.

Goldthorpe, John (2010). De la sociología. Números, narrativas e integración de la investigación y la teoría. Madrid: Centro de Investigaciones Sociológicas.

Hout, Michael (1983). Mobility Tables. Beverly Hills, California: Sage.

Hoyos, Rafael de; Martínez de la Calle, Juan M.; Székely, Miguel (2010). «Educación y movilidad social en México». En: Serrano Espinosa, Julio; Torche, Florencia (eds.). Movilidad social en México. Población, desarrollo y crecimiento. México, DF: Centro de Estudios Espinosa e Yglesias.

INEE (2018). Panorama Educativo de México 2017. Indicadores del Sistema Educativo Nacional. Educación básica y media superior. México: Instituto Nacional para la Evaluación de la Educación (INEE).

INEGI (2015). Principales resultados de la Encuesta Intercensal 2015: Estados Unidos Mexicanos. México: Instituto Nacional de Estadística y Geografía (INEGI).

- (2016). Módulo de Movilidad Social Intergeneracional 2016. Primeros resultados y bases metodológicas. México: Instituto Nacional de Estadística y Geografía (INEGI).

IsHIDA, Hiroshi (ed.) (2008). Social stratification and social mobility in late-industrializing countries. Tokyo: SSM Research Series 14.

JoRRAT, Raúl (2010). «Logros educacionales y movilidad educacional intergeneracional en Argentina». Revista Desarrollo Económico, 49 (196), 573-604.

LeOne, Tharcisio (2017). "The gender gap in intergenerational mobility: Evidence of educational persistence in Brazil». Diskussionsbeiträge, No. 2017/27, Freie Universität Berlin, Fachbereich Wirtschaftswissenschaft, Berlín. Recuperado de <https://www.econstor.eu/bitstream/10419/170574/1/100217953X.pdf>.

López, Mónica; Rodríguez, Santiago (2019). «Desigualdad de oportunidades educativas en México: evidencias en la educación media superior y superior». Lavboratorio Revista de Estudios sobre Cambio Estructural y Desigualdad Social. IIGG-UBA, 29, 60-86.

López-Roldán, Pedro; FaChelli, Sandra (2015). Metodología de la investigación social cuantitativa. Barcelona: Universitat Autònoma de Barcelona.

Mendoza Rojas, Javier (2018). Subsistemas de Educación Superior. Estadística básica 2006-2017. México: DGEI-UNAM.

Muñoz, Humberto; Oliveira, Orlandina de; Stern, Claudio (1977). Migración y desigualdad social en la ciudad de México. México: Instituto de Investigaciones Sociales-UNAM. 
Pfeffer, Fabian (2008). «Persistent Inequality in Educational Attainment and its Institutional Context». European Sociological Review, 24 (5), 543-565. $<$ https://doi.org/10.1093/esr/jcn026>.

Powers, Daniel; XIE, Yu (2000). Statistical Methods for Categorical Data Analysis. San Diego, California: Academic Press.

Rodríguez Gómez, Roberto (1999). «Expansión del sistema educativo superior en México, 1970-1995». En: Fresán Orozco, Magdalena (ed.). Tres décadas de políticas de Estado en educación superior. México: ANUIES.

Rodríguez, Santiago (2019). «Pautas absolutas de movilidad educativa intergeneracional en el México contemporáneo». Revista CoPala, 7, 125-142.

Ryder, Norman (1965). "The Cohort as a Concept in the Study of Social Change». American Sociological Review, 30 (6), 843-861. <https://doi.org/10.1007/978-1-4613-8536-3_2>.

SEP (2000). Perfil de la educación en México. México: Secretaria de Educación Pública (SEP).

- (2017). Principales cifras del Sistema Educativo Nacional 2016-2017. México: Secretaría de Educación Pública (SEP).

Sistema Nacional de Información Estadística y Geográfica (SNIEG) (2018). Catálogo Nacional de Indicadores. México. Recuperado de <https://www.snieg.mx/cni/>.

Solís, Patricio (2007). Inequidad y movilidad social en Monterrey. México DF: El Colegio de México.

- (2011). «Desigualdad y movilidad social en la Ciudad de México». Estudios Sociológicos, 29 (85), 283-298.

- (2013). «Desigualdad vertical y horizontal en las transiciones educativas en México». Estudios Sociológicos, 21, núm. extraordinario, 63-95.

- (2014). «Desigualdad social y efectos institucionales en las transiciones educativas». En: Blanco, Emilio; Solís, Patricio; Robles, Héctor (coord.). Caminos desiguales. Trayectorias educativas y laborales de los jóvenes en la Ciudad de México. México: El Colegio de México - INEE.

- (2016a). «Aspectos metodológicos en el análisis de la movilidad social». En: Solís, Patricio; BoAdo, Marcelo (coords.). Y sin embargo se mueve.... Estratificación social y movilidad intergeneracional de clase en América Latina. México: El Colegio de México - Centro de Estudios Espinosa Yglesias.

- (2016b). «Estratificación social y movilidad de clase en México a principios del siglo xxI». En: Solís, Patricio; Boado, Marcelo (coords.). Y sin embargo se mueve...: Estratificación social y movilidad intergeneracional de clase en América Latina. México: El Colegio de México - Centro de Estudios Espinosa Yglesias.

- (2018). Barreras estructurales a la movilidad social intergeneracional en México. Un enfoque multidimensional. Ciudad de México: CEPAL.

SzÉKELY, Miguel (2005). «Pobreza y desigualdad en México entre 1950 y 2004». El trimestre económico, 72 (288), 913-931.

Tam, Tony; Ganzeboom, Harry B. G. (2009). «Is Persistent Inequality a Mirage? Educational Opportunity over the Long Haul in 13 Societies». Extend abstract for the 2009 RC28 meeting in Beijing. Recuperado de <http://www.harryganzeboom. $\mathrm{nl} /$ Pdf/2009-Tam-Ganzeboom-ComparativeIEO-RC28-Beijing-(paper).pdf>.

Torche, Florencia (2010). «Cambio y persistencia de la movilidad intergeneracional en México». En: Serrano Espinosa, Julio; Torche, Florencia (eds.). Movilidad social en México. Población, desarrollo y crecimiento. México DF: Centro de Estudios Espinosa e Yglesias. 
Treiman, Donald (2009). Quantitative data analysis. Doing social research to test ideas. San Francisco, California: Jossey-Bass.

VAllet, Louis-André (2016). «¿Cómo podemos analizar la dinámica temporal en asociaciones estadísticas caracterizadas por una muy fuerte inercia? Avances recientes en el modelado log-multiplicativo». En: Jorrat, Jorge Raúl; colaboradores. De tal padre... ¿tal hijo? Estudios de movilidad social en Argentina. Buenos Aires: Editorial Dunken.

Yaschine Arroyo, Iliana (2015). ¿Oportunidades? Política social y movilidad intergeneracional en México. México DF: El Colegio de México y Universidad Nacional Autónoma de México.

\section{Anexo}

Matriz de diseño de los parámetros de cruces.

Cr1. Sin escolaridad y Primaria incompleta

\begin{tabular}{llllllll}
\hline & & \multicolumn{7}{c}{ Destinos } \\
\cline { 2 - 8 } & & $\mathbf{1}$ & 2 & 3 & 4 & 5 & 6 \\
\hline \multirow{3}{*}{ Orígenes } & 1 & 0 & 1 & 1 & 1 & 1 & 1 \\
& 2 & 1 & 0 & 0 & 0 & 0 & 0 \\
& 3 & 1 & 0 & 0 & 0 & 0 & 0 \\
& 4 & 1 & 0 & 0 & 0 & 0 & 0 \\
& 5 & 1 & 0 & 0 & 0 & 0 & 0 \\
& 6 & 1 & 0 & 0 & 0 & 0 & 0 \\
\hline
\end{tabular}

Cr2. Primaria incompleta y Primaria completa

\begin{tabular}{llllllll}
\hline & & \multicolumn{7}{c}{ Destinos } \\
\cline { 2 - 8 } & & $\mathbf{1}$ & $\mathbf{2}$ & $\mathbf{3}$ & $\mathbf{4}$ & $\mathbf{5}$ & 6 \\
\hline \multirow{3}{*}{ Orígenes } & $\mathbf{1}$ & 0 & 0 & 1 & 1 & 1 & 1 \\
& 2 & 0 & 0 & 1 & 1 & 1 & 1 \\
& 3 & 1 & 1 & 0 & 0 & 0 & 0 \\
& 4 & 1 & 1 & 0 & 0 & 0 & 0 \\
& 5 & 1 & 1 & 0 & 0 & 0 & 0 \\
& 6 & 1 & 1 & 0 & 0 & 0 & 0 \\
\hline
\end{tabular}

Cr3. Primaria completa y Secundaria

\begin{tabular}{llllllll}
\hline & \multicolumn{7}{c}{ Destinos } \\
\cline { 2 - 8 } & & $\mathbf{1}$ & $\mathbf{2}$ & $\mathbf{3}$ & $\mathbf{4}$ & $\mathbf{5}$ & $\mathbf{6}$ \\
\hline \multirow{3}{*}{ Orígenes } & 1 & 0 & 0 & 0 & 1 & 1 & 1 \\
& 2 & 0 & 0 & 0 & 1 & 1 & 1 \\
& 3 & 0 & 0 & 0 & 1 & 1 & 1 \\
& 4 & 1 & 1 & 1 & 0 & 0 & 0 \\
& 5 & 1 & 1 & 1 & 0 & 0 & 0 \\
& 6 & 1 & 1 & 1 & 0 & 0 & 0 \\
\hline
\end{tabular}


Cr4. Secundaria y EMS

\begin{tabular}{llllllll}
\hline & & \multicolumn{7}{c}{ Destinos } \\
\cline { 2 - 8 } Orígenes & $\mathbf{1}$ & 2 & 3 & 4 & 5 & 6 \\
& 1 & 0 & 0 & 0 & 0 & 1 & 1 \\
& 2 & 0 & 0 & 0 & 0 & 1 & 1 \\
& 3 & 0 & 0 & 0 & 0 & 1 & 1 \\
& 4 & 0 & 0 & 0 & 0 & 1 & 1 \\
& 5 & 1 & 1 & 1 & 1 & 0 & 0 \\
& 6 & 1 & 1 & 1 & 1 & 0 & 0 \\
\hline
\end{tabular}

Cr5. EMS y Superior

\begin{tabular}{llllllll}
\hline & & \multicolumn{7}{c}{ Destinos } \\
\cline { 2 - 8 } & & $\mathbf{1}$ & 2 & 3 & 4 & 5 & 6 \\
\hline \multirow{3}{*}{ Orígenes } & 1 & 0 & 0 & 0 & 0 & 0 & 1 \\
& 2 & 0 & 0 & 0 & 0 & 0 & 1 \\
& 3 & 0 & 0 & 0 & 0 & 0 & 1 \\
& 4 & 0 & 0 & 0 & 0 & 0 & 1 \\
& 5 & 0 & 0 & 0 & 0 & 0 & 1 \\
& 6 & 1 & 1 & 1 & 1 & 1 & 0 \\
\hline
\end{tabular}

